\title{
La prensa como vehículo de la historia del eucalipto en Galicia
}

\author{
Fernando RAmos FeRnÁNDEZ \\ Universidad de Vigo \\ ferramos@telefonica.net \\ David Caldevilla Domínguez \\ Universidad de Complutense \\ davidcaldevilla@ccinf.ucm.es
}

\section{Resumen:}

Es largo el recorrido de la polémica en torno al Eucalipto en Galicia. La diatriba sobre la conveniencia de su cultivo nunca ha cesado realmente, y los medios de comunicación locales son en buena medida responsable de mantener el litigio público abierto.

Palabras clave: Eucalipto; Galicia; Eume; Madera; Xunta de Galicia

\section{History and evolution of Eucalyrtu's image in Galician press}

\begin{abstract}
:
The debate around Eucalyptus in Galicia has a long way behind it. The discussion about it's cultive's convenience has never really ceased, and galician media are, in good part, responsible for the debate's continous existance.
\end{abstract}

Key Words: Eucalypt; Galicia; Eume; Wood; Xunta of Galicia

\section{Referencia normalizada:}

Ramos Fernández, F. y Caldevilla Domínguez, D. (2014): La prensa como vehículo de la historia del eucalipto en Galicia. Historia y Comunicación Social. Vol. 19. Núm. Especial Marzo. Págs. 715-728.

Sumario: 1. Introducción 2. Metodología 3. Desarrollo: Historia de una imagen secular 3.1. La presión sobre los montes por la construcción naval. 3.2. La recuperación de la conciencia forestal 3.3. Un fraile gallego importa el eucalipto 4. La importancia económica de la madera gallega en la fabricación de pasta de papel 5. La controversia sobre el eucalipto. El caso de las "Fragas del Eume" como paradigma 6. Las razones de los defensores del eucalipto 6.1. Estudios que defienden al eucalipto 6.2. Los ecologistas no se rinden 7. Conclusiones 8. Bibliografía 


\section{Introducción}

La naturaleza $a b$ origine de la comunicación la convierte en una herramienta intrinsecamente persuasiva. Dispone de lo necesario para crear imágenes inconscientes en la mentalidad popular, así como sensaciones. Y esto la convierte en una herramienta de gran poder, para lo bueno y para lo malo; es decir: en función del autor que la esgrima. Cualquier actividad humana está sujeta a este peligro, con total independencia de lo nimio que pueda parecer el tema concreto en el contexto general de la sociedad. La Opinión Pública acaba coincidiendo con la Opinión Publicada cuando esta última es omnímoda (Caldevilla, 2007).

Nuestro estudio aborda un asunto adornado de un prolongado historial de controversia en Galicia, el pulmón verde de la península: porque se aúnan en él posturas opuestas con intereses políticos y económicos, no siempre conocidos evidentes para el ciudadano medio.

La 'Tierra de Breogán' contiene en torno a los 2.000.000 de hectáreas de superficie de bosques, de esos dos millones, el $70 \%$ es masa arbolada y el $30 \%$, monte de arbolado disperso, matorral, pastizal, etc. Estamos hablando del 7\% de la superficie total del país, pero en este 7\% se realiza la mitad de todas las talas del país, lo que es indicativo claro de la importancia del sector maderero gallego, que sufre históricamente dos lacras; los habituales incendios forestales y la sempiterna controversia entre los defensores del bosque autóctono -frondosas y otras especies nobles, y de larga espera para su maduración y aprovechamiento- que ven en el eucalipto una especie intrusa, y aquellos que lo reivindican y promueven. En la última década, muchos han salido al paso de la mala prensa de este "árbol maldito" contra el que incluso la administración ha tomado medidas en más de una ocasión.

Las campañas mediáticas contra el eucalipto, a menudo, no cumplen el deber de veracidad y contraste que obliga a medios y periodistas, tal y como reflejan los trabajos de Flores Gómez y Mendieta Ramírez (2012: 3)

Los medios deben presentar la información de tal modo que sus ejemplares motiven a la reflexión; para esto deben ser sobrios y permitir que sus líneas sean legibles e inteligibles para sus seguidores, es decir, el medio debe persuadir al lector de adquirirlo todos los días con la calidad de sus contenidos, esto es, con la noticia pertinente redactada sobria y clara.

En este caso concreto, el sensacionalismo es más generalizado de lo esperable. Como nos recuerda la profesora Busto Salinas porque "Se observa que cuanto más pequeño es el ámbito de difusión de un diario, mayores posibilidades existen de que una nota de prensa sea divulgada" (Busto Salinas, 2012: 73) en la prensa gallega, colocar este tipo de notas es muy habitual, dándonos lugar a hablar de campaña sin paliativos.

La Xunta de Galicia, teniendo competencias en el tema, ha elaborado una política contra los eucaliptos. No se permite plantarlos en zonas de bosques autóctonos, ni intercalar estas especies, con árboles frondosos caducifolios, como castaños, robles, 
nogales o alisos. Y, en caso de incendio, tampoco está permitida la repoblación forestal con eucaliptos. Es obligatorio solicitar un informe de impacto ambiental para plantar un eucaliptal de más de 5 hectáreas.

La Ley de Montes de Galicia establece que su zona de influencia es la mayor potencia forestal del país y una de las mayores del continente. Su superficie total arbolada supone el $48 \%$ de la de la Comunidad Autónoma, con más de 1.400.000 hectáreas y una elevada producción de madera.

Por esto el incremento de la masa arbolada constituye un objetivo ineludible, del sector forestal, y de la sociedad gallega, garantizando el aprovechamiento continuado unos recursos que siguen siendo, el segundo bien deficitario en la Unión Europea tras la energía. La madera puede suponer una vía de económica ordenación de la zona que ponga freno al abandono rural en Galicia.

El eucalipto crece al máximo en su introducción durante la Dictadura franquista, y en los noventa su plantación se subvencionó. Según Greenpeace, podrían suponer 245.000 hectáreas de monte gallego. De los 600.000 propietarios forestales de la comunidad, al menos 120.000 administran fincas con eucaliptos. Su rápido crecimiento es la baza económica respecto a otras especies de explotación maderera. Sin embargo, persiste la idea de que ha ido ganando terreno a costa de las especies autóctonas, de que empobrece los suelos y de que favorece los incendios. Pero otros entienden que este árbol ha gozado de una inmerecida mala fama.

Ante una melee de argumentos sentimentales, política y controversia científica, los datos objetivos dicen que en 50 años el bosque autóctono se ha recortado en un $20 \%$ junto con buena parte de su biodiversidad. Pero existen otras causas: plagas, cambio climático, y el abandono y despoblamiento del medio rural, son la base de una realidad altamente inquietante, dentro de una comunidad con dos tercios de superficie forestal.

Boo (2012: 557 y ss) discrepa de la opinión generalizada sobre la plantación masiva de eucaliptos durante el régimen de Franco ya que el $80 \%$ de esas plantaciones las hicieron propietarios privados.

En 1992, un comprometido catedrático de sociología de la Universidad de Santiago, el profesor Pérez Vilariño, llevó a cabo un estudio sobre este árbol, entre el profesorado no universitario y las gentes corrientes, en general (1992: 19 y ss). El resultado fue que $91 \%$ de los profesores encuestados y el $78 \%$ de la población respondieron que los eucaliptos empobrecen el suelo; el $75 \%$ de los primeros y el $66 \%$ de los segundos opinaron que el terreno donde se plantan eucaliptos ya no puede servir para otros usos; el $80 \%$ y 64\%, respectivamente, consideraron incompatible el eucalipto con la ganadería; y el 75\% de los docentes y el $76 \%$ de los ciudadanos dijeron que el eucalipto consume más agua que las demás especies.

Como precedente en 1991, se había realizado la Encuesta de Cultura Forestal (ECF) por parte de las empresas Alef-Millward Brown y Servicios e Inicia- 
tivas Forestales (SESFOR), atendiendo un encargo de la Xunta de Galicia. El trabajo de campo consistió en 2.570 entrevistas y se llevó a cabo con un margen de error del 1,97\%. Entre otras cuestiones, se solicitó de los encuestados que manifestasen su acuerdo o desacuerdo con una serie de proposiciones relacionadas con el eucalipto, recopiladas en artículos de prensa publicados entre 1989 y 1990. El 78\% de los sondeados se mostró "muy" o "bastante de acuerdo" con lo publicado por los medios de comunicación. La Opinión Pública y la Opinión Publicada volvían a coincidir (Caldevilla, 2007)

\section{Metodología}

Para comprender la mala fama del eucalipto, especialmente desarrollada en los últimos treinta años, es preciso no sólo seguir las crónicas periodísticas que se han ocupado de este asunto en la prensa gallega, sino sobre todo la propia historia reciente del proceso de deforestación y repoblación que tiene lugar en España, en general, y en Galicia en particular. Se precisaban especies de rápido crecimiento y aprovechamiento inmediato. El estudio de estos procesos es indispensable para situarnos ante lo que el investigador Miguel Boo $(2012,2)$, ha llamado la "Mala prensa del eucalipto", tras investigar las noticias más negativas sobre esta especie aparecida en " $\mathrm{La}$ Voz de Galicia", el diario de mayor tirada e influencia a lo largo del debate que llega hasta hoy. Este árbol denostado aparece, paradójicamente, como elemento reactivador de la economía forestal gallega.

Partimos como precedente de la Encuesta de Cultura Forestal (ECF) por parte de las empresas Alef-Millward Brown y Servicios e Iniciativas Forestales (SESFOR), atendiendo un encargo de la Xunta de Galicia, realizada en 1991. Ponemos en relación los tres aspectos relatados: deforestación salvaje, repoblación tardía y controversia sobre la repoblación masiva de eucaliptos en un país de robles y castaños. Sobre esta polémica se proyectan los indudables beneficios económicos que la explotación del eucalipto brinda a Galicia, como árbol del que sale su elevada producción de pasta de papel. Pero los ecologistas, encabezados por Greenpeace no lo aceptan. Hemos contrapuesto las más recientes manifestaciones de unos y otros en esta interminable polémica, en la que la propia Administración ha terciado, limitando los espacios donde se pueda cultivar eucaliptos: dos tercios del territorio de la Comunidad gallega le están vetados. 


\section{Historia de una imagen secular}

\subsection{La presión sobre los montes por la construcción naval}

Los montes de España fueron sistemáticamente esquilmados a lo largo de varios siglos por su dilatada historia bélica y naval, especialmente desde el XVI al XIX.

Pero ya en 1811 (Castillo, 1992:135) se daba la voz de alarma sobre el espectacular descenso de la masa arbolada del país, no tanto porque hubiera surgido conciencia ecologista, sino por la demanda de madera que precisaba mantener una adecuada escuadra nacional. Se puso en marcha una política de cesión a las poblaciones de los denominados "montes de realengo" (propiedad del Rey) en orden a facilitar la vida de las familias pobres, a cambio de que éstas ayudasen a incrementar la riqueza del ámbito rural y a repoblar espacios vacíos de amplios territorios. Consecuentemente, conforme a las necesidades de la Armada, se dictaron normas que dejan pocas dudas. Si los árboles del dominio real no llegasen, se tomarían los de los particulares. Y si los propietarios no aceptasen el precio justo, dispuesto por el Estado, se tomaría el más adecuado, "procurado que no toda la madera sea de un mismo dueño".

\subsection{La recuperación de la conciencia forestal}

A partir de la Ley de Fomento y Conservación de los Montes de 1908, España recupera la conciencia de que es precisa la recuperación de su patrimonio forestal, según recuerda Torre (2009: 17). Se producen unas iniciativas legislativas de enorme alcance. Se propugna no sólo un uso razonable del bosque, sino que surgen por todo el país Asociaciones de Amigos del Bosque y de los Árboles.

No obstante, los paisanos de las zonas donde se llevaron a cabo las repoblaciones no siempre reaccionaron con el mismo calor, pues estaban habituados a ser los únicos administradores de los montes, basándose en usos antiguos y una curiosidad jurídica: Más del 70 por ciento de los montes de Galicia son denominados "Montes de Vecinos", conforme al derecho germánico, en el sentido de que los montes pertenecen a las comunidades parroquiales, no a los ayuntamientos, de manera colectiva, sin asignación de cuotas, de modo que el uso, usufructo y aprovechamiento corresponde a los residentes en un determinados lugar.

Con la llegada de la II República y su afán modernizador, España recuperó la conciencia de que la repoblación forestal de los esquilmados montes del país era una tarea urgente. Este objetivo (Torre 2009: 68) fue asumido como tarea prioritaria por el Partido Socialista y por el Partido Galleguista. Los grandes visionarios del nacionalismo gallego, Castelao y Bóveda, escribían sobre la Galicia del futuro como una región eminentemente forestal, papelera y productora de leche y productos agropecuarios (Castelao: 1944).

En aquel momento (Torre, 2009: 70 y ss.), la mayor parte de la producción de los montes de la zona interior de Galicia estaba en manos de particulares, y el roble (Quercus pedunculata) era la especie dominante. Se usaba esencialmente para la 
fabricación de traviesas de madera, destinadas al ferrocarril. La falta de un estudio serio sobre el proceso de crecimiento del árbol gallego por excelencia no permitía un cálculo preciso de su rendimiento económico. El nogal se empleaba en ebanistería y en la construcción de hélices para aeroplanos. El Pinus Pinaster se empleaba en la construcción, minas, cajones. El vigoroso castaño iba perdiendo uso en la construcción, amenazado además por la enfermedad de la tinta. Era muy usado el abedul, cuya demanda crecía junto al aliso, si bien el primero se empleaba para zuecos, arados, carros y otras piezas de la etnografía popular.

\subsection{Un fraile gallego importa el eucalipto}

No deja de ser una curiosa paradoja de la historia que este árbol tan denostado en Galicia y tan presente en su reciente historia forestal fuera importando precisamente por un gallego. Fernández (2011) sostiene al efecto sobre la llegada de las primeras semillas del eucalipto:

Lo más probable es que hubiesen sido traídas o enviadas por Rosendo Salvado, obispo en aquellas tierras de las antípodas [Australia] en torno a 1860 (...) lo que supondría además que las de Tui serían las primeras plantaciones de eucaliptos hechas en España.

En aquellos años, Europa estaba habituada a recibir plantas exóticas procedentes de todos los continentes, y el eucalipto fue una más.

\section{La importancia económica de la madera gallega en la fabricación de pasta de papel}

Según la Red de Información Forestal para Europa sobre la cadena empresarial de la madera en Galicia, en esta región existe actualmente una planta de pasta de celulosa, una planta de fabricación de papel y cartón, cuatro plantas de transformación de cartón y cartoncillo, y veinticinco empresas manipuladoras de elementos de papel y cartón, siendo los principales productos de este subsector papelería y material de oficina, y envases y embalajes de cartón. Los principales receptores de estos productos derivados son el mercado gallego (64\%) y el nacional (23\%), con una limitada exportación a la Unión Europea (13\%), significativa en el contexto de la Cadena de Galicia.

En conjunto, todo el sector factura algo más de 210 millones de euros y da empleo directo a cerca de 900 personas sin contar los trabajadores forestales y los de las empresas suministradoras de materia prima.

La fábrica de pasta, perteneciente al grupo ENCE, que cuenta con una capacidad de producción nominal de 310.000 toneladas/año, consume 0,9 millones de $\mathrm{m}^{3}$ de Eucalyptus globulus y genera 482 empleos directos, facturando 144 millones de 
Euros. La producción de pasta de celulosa, papel, y cartón en Galicia supone el $18 \%$ del total de España.

Existe una importante industria de primera transformación y una escasa elaboración de productos de segunda y tercera transformación, existiendo una ruptura en la cadena ya que toda la pasta fabricada en Galicia se exporta, destinándose sólo el 5\% al mercado español.

Uno de los puntos fuertes de este subsector es esa destacada actividad exportadora de la industria de pasta de papel. Se exporta el $75 \%$ de la producción a Alemania, Austria, Suiza y Reino Unido.

\section{La controversia sobre el eucalipto. El caso de las "Fragas del eume" como paradigma}

Como ejemplo de la contraposición entre lo que se considera bosque natural de Galicia y agresión al medio ambiente de una especie importada, se cita el caso del ecosistema de las "Fragas del Eume". Un equipo de investigadores de la Universidad Rey Juan Carlos de Madrid analizó minuciosamente este espacio, considerado uno de los bosques mejor conservados de toda la franja costera de la Europa atlántica.

El estudio partió de una estrategia metodológica científica ya desarrollada por autores como González Loureiro (2012: 126)

basada en: a) Transferir información actualizada y bien organizada procedente de diversas fuentes, b) Facilitar la comprensión y aplicación de los procedimientos específicos y c) Elevar la motivación de los estudiantes.

La investigación estableció que la reducción de bosque autóctono en las fragas es extrapolable para todo el territorio gallego, aunque en la comunidad la cifra del $20 \%$ aún podría ser más elevada. Es uno de los más recientes y consistentes estudios sobre los efectos negativos del eucalipto, de gran valor de referencia para los críticos.

El grupo del departamento de Biología y Geología del citado centro comparó las fotos aéreas tomadas por los vuelos del Ejército estadounidense en los años 1956 y 1957 con las del Sistema de Información Geográfica de Parcelas Agrícolas (SIGPAC) del año 2002. Las imágenes muestran una radical disminución del bosque de ribera de avellanos y alisos que se ha recortado en 48 kilómetros, según los cálculos de los investigadores.

El bosque autóctono de macizos frondosos también ha sufrido una merma de 647 hectáreas. Las fragas se ven afectadas por la deforestación que se ha incrementado en un $41,1 \%$ en los últimos 50 años. De las casi 9.000 hectáreas que conforman el Parque Natural de las "Fragas del Eume", la zona de bosque no llega a las 3.000 (López Teixido et al, 2009: 60-73). Pese a su deterioro, este espacio conserva gran 
valor ecológico y alberga varias especies protegidas tanto por la Unión Europea como por la Unión Internacional de Conservación de la Naturaleza (UICN).

Además del impacto de la actividad industrial -la construcción del embalse y las zonas mineras- en opinión de los investigadores la gran amenaza de las fragas es el eucalipto. Hace cinco décadas la superficie ocupada por esta especie introducida en Galicia en el siglo XIX suponía solo el 6,9\%, pero actualmente ocupa el 20\% del parque.

Hay dos problemas fundamentales: la plantación y la extensión del eucalipto", -afirma López Teixido-: el eucalipto tiene gran capacidad para dispersarse e invadir otro tipo de bosques. Sus semillas son pequeñas lo que facilita que el aire las desplace con facilidad y sus grandes raíces logran absorber más agua que las otras especies arbóreas y eliminan a sus competidores. En las fragas, el eucalipto está fragmentando el bosque autóctono que ha logrado resistir. Es grave porque los bosques albergan más especies que, al tener que vivir en una superficie cada vez más pequeña, encuentran más dificultades.

El 31 de marzo de 2012 y días sucesivos, hasta que pudo ser controlado, un voraz incendio destruyó gran parte de la riqueza forestal de este parque natural, quemándose 750 hectáreas de superficie, de ellas 500 de arbolado.

\section{Las razones de los defensores del eucalipto}

Pero frente a estas tesis que repudian al eucalipto, otras sostienen justamente lo contrario. Tal es el caso de Boo (2012: 554), quien se ha dedicado a desmitificar la mala fama de esta especie, a partir de lo que denomina una sucesión de mitos. Esos mitos, son, según su defensor: que es enemigo del suelo, que no es compatible con otros cultivos, que no protege de las erosiones, que es voraz con los manantiales y agota el agua, que es el moto pirofito y favorece el negocio de la tierra quemada; que es una especie alóctona y antinatural, que perjudica al medio ambiente, que sólo vale para la celulosa. Además, que atenta contra la biodiversidad y la salud y que genera ruina y obliga al desplazamiento de poblaciones.

Sostiene Boo que el eucalipto ha venido padeciendo todos los efectos perniciosos que se derivan de haber sido víctima de un periodismo alejado de las directrices de los expertos, de los investigadores y de los científicos, y alimentado por determinadas siglas políticas que difundieron información interesada, desenfocada y distorsionada sobre la realidad de este árbol, y que los medios no divulgaron el conocimiento del saber científico, prefiriendo - prácticamente en exclusiva- las versiones de organizaciones ecologistas, vecinales, políticas y/o sindicales. Incluso apunta a que las supuestas campañas de descrédito contra eucalipto se sospecha la influencia del capital maderero nórdico, temerosos de las potencialidades de la especie en un clima y en un suelo como el atlántico peninsular. 
Y en defensa de su tesis subraya que si comparamos las plantaciones de eucalipto con las de robles y pinos, la diferencia de fertilidad de los suelos es escasa. Antes, al contrario, el eucalipto consigue mantener una microflora abundante y variada que ayuda a descomponer residuos e incorporarlos al sistema nutritivo. E insiste en que las alteraciones en la parte mineral del suelo bajo de eucaliptos no son superiores a las registradas bajo frondosas, lo que desmiente, a su entender, el agotamiento que en los medios se le ha venido achacando a los eucaliptales. Siempre según Boo: No existe incompatibilidad entre el eucalipto y cualquier especie de las denominadas autóctonas.

Sostiene que, por lo que se refiere al supuesto agotamiento de las reservas hídricas que tan profusamente se le ha venido imputando al eucalipto estamos ante otro mito: "Se ha demostrado empíricamente que, en verano, la demanda de agua de pinos, eucaliptos y robles es similar". (Boo, 2012: 557 y ss.)

\subsection{Estudios que defienden al eucalipto}

Casi la totalidad de los suelos de Galicia presentan un carácter ácido [con un $\mathrm{pH}$ entre 4,5 y 5,5]. Los datos de que se dispone no permiten señalar diferencias significativas entre distintas especies forestales (Calvo de Anta (1995: 239.). La investigación que analiza la posible degradación de las propiedades intrínsecas del suelo debido al desarrollo del Eucalipto globulus en Galicia, entiende por degradación edáfica "la pérdida o transformación de las propiedades del suelo, acelerando o provocando un descenso de su fertilidad física o química hasta un estado que impida, en el futuro, el desarrollo de otros usos". Y añade que, en cuanto a la fertilidad de los suelos gallegos, "son muy ligeras las diferencias entre robledales, pinares y eucaliptales".

En su campaña desmitificadora sobre la mala imagen del Eucalipto, Boo invoca los argumentos del director del Centro de Investigación e Información Ambiental de Lourizán (Pontevedra), José A. Vega Hidalgo y la bióloga Cristina Fernández Filgueira (2002: 20.), quienes afirman que impresiona ver la facilidad con que por parte de ciertos grupos ecologistas, algunos medios de comunicación y sectores de opinión, pueden lanzarse rápidamente aseveraciones negativas sobre uno u otro tema medioambiental o, como en el caso del eucalipto, sobre una especie, sin ningún apoyo científico.

En la misma línea argumental Boo sostiene que no se puede atribuir a una especie forestal concreta la responsabilidad de ser la principal causante de los incendios forestales. Y dice al respecto que la FAO, llegó a proponer el uso de los eucaliptos como torres de vigilancia de los incendios. En cuanto al aprovechamiento de la madera quemada, parece demostrado que en el caso del eucalipto presenta dificultades añadidas, no sólo por el encarecimiento de su manipulado, sino porque no es útil para la fabricación de celulosa.

Frente al mito de que lo alóctono es malo y lo autóctono bueno, afirma que en el medio forestal que todo viene a ser alóctono, y que donde hoy hay una frondosa 
antes hubo habitualmente una conífera: "Si hubiera que eliminar los eucaliptos por ser alóctonos, por coherencia estaríamos obligados a hacer lo propio con el maíz, la patata, el tomate, el pimiento, el tabaco, el girasol, el arroz, las naranjas o el kiwi”.

El eucalipto no sólo no perjudica al medio ambiente sino que es respetuoso con él, alberga una fauna y una flora peculiares, realiza funciones correctoras hidro-forestales, y actúa como protector acústico, como cortavientos o como cortina que evita la insolación del ganado. El eucalipto se ha revelado como una de las especies más capaces de "secuestrar" $\mathrm{CO}_{2}$ y gases de efecto invernadero, para así liberar oxígeno a la atmósfera, insiste Boo (2012: 274 y ss.).

El repertorio o catálogo de posibilidades que esta madera ofrece, no se agota en las consabidas apeas para minas, traviesas de ferrocarril, bateas de mejillón; cercas, vallados o postes; sino que también se usa para la fabricación de puertas, ventanas o muebles, los conocidos parqués de "Roble de Tasmania" (eufemismo europeo del eucalipto australiano) o los salpicaderos de coches de alta gama, alemanes y estadounidenses, porque la madera de esta especie posee, según los expertos, propiedades mecánicas superiores a las del roble.

En su haber positivo, sus defensores destacan los servicios que el eucalipto ha rendido y sigue rindiendo a la salud: “(...) por haberse empleado sus hojas y aceites esenciales, por parte de las industrias químicas y farmacéuticas o confiteras, en funciones salutíferas de tipo analgésico, antisépticos, cicatrizante, desodorantes, diurético, etc."

Boo (2012: 554) concluye que la explotación del eucalipto atiende a la demanda cada vez mayor de papel en el mundo y que lejos de traer la ruina, el eucalipto es una madera tradicionalmente rentable por su altísima producción por hectárea y año.

De juicios asentados sobre la razón científica se obtiene una imagen muy distinta a la que parecen poseer generalmente los gallegos. (Lage: 2003: 200). Los componentes afectivos actúan seleccionando y/o transformando las informaciones sobre el eucalipto, buscando su asimilación coherente junto a los valores y estructuras de pensamiento social establecido. Si al eucalipto se le vincula, por ejemplo, con la transformación del paisaje, las fabricación de pasta de celulosa o de papel, y/o la incidencia de los incendios forestales, en el pensamiento social se despiertan suspicacias que predisponen respecto a cómo interpretar sus significados, insistiendo en manejar argumentos contrarios al mismo. (...)

El predominio de un lenguaje tan "demonizador" en los medios de comunicación sobre el eucalipto, impide la emergencia de mensajes más profesionalizados, entre otras razones porque las connotaciones simbólicas del discurso empleado contra el eucalipto por nacionalistas y ecologistas "han inclinado a no pocos políticos a la ambigüedad y la indecisión” (Vilariño, 1992: 104).

Montero de Burgos $(1990,22)$ asegura que en medios periodísticos se han difundido una serie de mitos con los supuestos efectos negativos causado por esta especie, para concluir que estas pretendidas maldades publicadas sobre el eucalipto: "No se encuentran avalados por estudios o investigaciones contrastables [...] Es decir, no se 
encuentra bibliografia al respecto". Ello da lugar al predominio del discurso valorativo de carácter polémico frente al profesional". En su opinión, entre los gallegos había calado ya entonces un discurso asaz distante de los conceptos científico, técnico y profesional que rigen el sector.

\subsection{Los ecologistas no se rinden}

Pese a todos los argumentos científicos aquí expuestos, los ecologistas no se rinden. Y su resistencia no sólo se sitúa en Galicia, sino en el resto de España. En vísperas del Día Forestal Mundial, el 17 de marzo de 2011, más de 20 organizaciones de conservación de la naturaleza y colectivos ecologistas de carácter estatal y de Andalucía, Galicia, Principado de Asturias, Cantabria y el País Vasco presentaron "Una Visión Común sobre el problema de las plantaciones de eucalipto", cuyo contenido mantienen año tras año.

Podríamos decir que el colectivo ecologista está actuando como lobby y no sólo, como apunta Caldevilla (2010: 38) porque "todo estudio sobre comunicación persuasiva se basa en el control ejercido sobre los medios por parte de los poderes económicos y políticos" sino porque el análisis de contenidos de sus comunicados sí mantiene una sesgada tendencia anti-eucalipto, sin aceptar puntos pro-eucalipto en el debate.

Actualmente, las masas puras y mixtas de eucalipto han llegado a ocupar más de 760.000 hectáreas en toda España. Tras Galicia, la región con más superficie de eucalipto de la península ibérica es Andalucía (156.000 ha), seguida de Extremadura (75.000 ha), Cantabria (60.000 ha), Asturias (58.000 ha) y el País Vasco (14.500 ha). Estas plantaciones suponen el $7 \%$ de la superficie mundial de plantaciones de eucalipto.

El manifiesto "Una Visión Común sobre el problema de las plantaciones de eucalipto" recoge un conjunto de demandas elaboradas por el movimiento ecologista con el asesoramiento de una parte de la comunidad científica, que abogan por una ordenación racional del sector. El manifiesto recoge 8 grandes directrices:

1. Fijar un límite de ocupación del territorio basado en criterios científico-técnicos, respeto a la planificación forestal, las estrategias y planes de ordenación del territorio y la legislación ambiental.

2. Prohibición de nuevas plantaciones en espacios naturales protegidos y eliminación progresiva de las existentes.

3. Establecer directrices de gestión específicas con indicadores para reducir significativamente los impactos negativos del modelo de gestión de los eucaliptales.

4. Incrementar y mejorar la investigación independiente sobre gestión forestal aplicable a las plantaciones de eucalipto en la península Ibérica. 
5. Utilizar la certificación forestal del FSC (Forest Stewardship Council) como una de las herramientas posibles para mejorar la gestión de las plantaciones de eucalipto.

6. No autorizar el desarrollo de plantaciones de eucaliptos transgénicos.

7. No considerar las plantaciones de eucalipto como solución al cambio climático.

8. El compromiso de la sociedad con la reducción del consumo de papel y de energía.

El manifiesto concluye: "Nuestras demandas señalan una hoja de ruta hacia donde debe encaminarse el sector y el futuro de las superficies ocupadas por eucalipto. Deberíamos empezar por dejar de plantar eucaliptos en los espacios protegidos y en los hábitats de especies amenazadas".

\section{Conclusiones}

Pese a su peso económico y a las ventajas que supone respecto a la explotación forestal de los terrenos donde se planta, el eucalipto es un árbol mal acogido por la opinión pública española, en general, y sobre todo por la gallega, pese a los beneficios que, en todos los aspectos, suponen. Ha nacido una corriente de pensamiento pseudo-científica en los medios de comunicación para masas, espoleados por intereses políticos, a los que las Relaciones Públicas no son nada ajenas (Caldevilla, 2005), y que han conducido a tomas de posición irreconciliables

En el campo puramente científico, la controversia constantemente alimentada por ambas partes, sitúa en el enfrentamiento, principalmente, a los ingenieros forestales y químicos, y por otro lado a ecologistas, movimientos políticos nacionalistas, de izquierda y gran parte de la población.

Flotando sobre todo ello, se aprecia un fenómeno de carácter sentimental e identitario, en torno a las masas forestales de frondosas que dibuja el paisaje tradicional de Galicia y su conservación, reduciendo para ello el espacio de eucaliptales a un marco limitado.

La conclusión más clara es que nada parece indicar que vaya a cesar el debate a corto o medio plazo, pues de manera regular, desde ambas posiciones enfrentadas, surgen nuevos argumentos para alimentar la caldera de la controversia. 


\section{Bibliografía}

\subsection{Libros:}

ALONSO SANTOS, M. (1985): Efectos ecológicos del Eucalyptus globulus en Galicia. Madrid. Instituto Nacional de Investigaciones Agrarias.

ANÓNIMO (1913): El eucalipto (Monografía divulgadora). La Coruña. Sociedad de Amigos de los Árboles de La Coruña.

BOO, M. (2012): La mala prensa del Eucalipto. Pontevedra. Tesis Doctoral. Escuela de Ingenieros Forestales. Universidad de Vigo.

CALDEVILLA DOMÍNGUEZ, D. (2005). Las Relaciones Públicas y su fundamentación. Madrid. Visionnet.

CALDEVILLA DOMÍNGUEZ, D. (2007). Manual de Relaciones Públicas. Madrid. Visionnet.

CASTELAO, A. D. (1944): Sempre en Galiza. Buenos Aires. Edicións Galiza.

CASTILLO MANRUBIA, P. (1992): La Marina de Guerra española en el primer tercio del siglo XIX. Madrid. Editorial Naval.

GOES, E. (1977): Os eucaliptos. Lisboa. Portucel.

MONTERO DE BURGOS, J. L. (1990): El eucalipto en España. Madrid. Ministerio de Agricultura-ICONA.

MONTOYA OLIVER, J. M. (1995): El eucalipto. Bilbao.

Ediciones Mundi Prensa.

LAGE PICOS, X. A. (2003): Bosques, sociedad y cultura forestal en Galicia. Vigo. Universidade de Vigo.

LÓPEZ TORRE, R. (2009): La reforestación de Pontevedra. Pontevedra. Servicio de Publicaciones de la Diputación Provincial.

VEGA HIDALGO, G. et al. (2002): Socioeconomía, tecnología, patología y sostenibilidad del eucalipto: Actas del Simposio internacional, del 9 de mayo al 21 de junio de 2002. Vigo. Cátedra. ENCE. Ed. Grupo de Investigación AF-4. Universidad de Vigo.

8.2 Artículos en libros o revistas en papel:

CALVO DE ANTA, R. (1992): "El eucalipto y las propiedades del suelo en Galicia" en Cuadernos de Ciencias Biológicas. Seminario de Estudos Galegos. Santiago de Compostela.

LÓPEZ TEIXIDO, A. et al (2009): Fragmentación del bosque y pérdida del hábitat de helechos amenazados en el Parque Natural Fragas do Eume (NW de España), en Ecosistemas. Vol. 18, n. 1 (en.-abr. 2009).

PÉREZ VILARIÑO, J. (1992): Cultura forestal y diferenciación profesional, en Revista Española de Investigaciones Sociológicas, no 59. Julio-septiembre 1992.

8.3 Artículos en publicaciones web:

BUSTO SALINAS, L. (2012): Uso y modificación de las notas de prensa dependiendo de las características de los periódicos, en Revista Vivat Academia, no espe- 
cial de febrero. Disponible en: www.ucm.es/info/vivataca/numeros/n117E/PDFs/ LBusto.pdf. Consultado el 15 de agosto de 2013.

CALDEVILLA DOMÍNGUEZ, D. \& OÑATE GONZÁLEZ, C. (2010). Los lobbies y el debate sobre las drogas: una imagen en cuestión, en Revista de la SEECI, $\mathrm{n}^{\circ}$ 23. Disponible en: www.seeci.net/seeci/Numeros/Numero\%2023/DaCris.pdf. Consultado el 22 de agosto de 2013.

FERNÁNDEZ, M. Á. (2011): La llegada del eucalipto a Galicia, en Galicia Agraria. Disponible en: http:/galiciaagraria.blogspot.com.es/2011/10/el-eucalipto-y-su-conquista-del.html. Consultado el 22 de agosto de 2013.

FLORES GÓMEZ, L. \& MENDIETA RAMÍREZ, A. (2012): La percepción de la nota roja periodística en primera plana. Un estudio de caso, en Revista de la SEECI, $n^{0}$ 27. Disponible en: www.seeci.net/seeci/Numeros/Numero\%2027/Varios1.pdf. Consultado el 16 de agosto de 2013.

GONZÁLEZ LOUREIRO, M. (2012): Nuevos sistemas para la evaluación continua del rendimiento del alumnado. Estudio de caso del coaching en el grado de ingeniería forestal, en Revista Vivat Academia, $\mathrm{n}^{\circ}$ especial de febrero. Disponible en: www.ucm.es/info/vivataca/numeros/n117E/PDFs/MGonza.pdf. Consultado el 22 de septiembre de 2013.

GREENPEACE ESPAÑA (2011): Los ecologistas proponen soluciones para acabar con el problema de las plantaciones de eucalipto. Disponible en: www. greenpeace.org/espana/es/news/Los-ecologistas-proponen-soluciones-para-acabar-con-el-problema-de-las-plantaciones-de-eucalipto/ Consultado el 7 de agosto de 2013.

PICOS, JUAN (2013) Producción de eucalipto en Galicia: guía de superviovencia. Universidad de Huelva. Disponible en www.uhu.es/cideu/JORNADAS09/JPicos. pdf Consultado 26/12/2013

RED DE INFORMACIÓN FORESTAL PARA EUROPA (2012): Cadena empresarial de la madera en Galicia. Disponible en: www.um.es/gtiweb/adrico/medioambiente/madera\%20galicia.htm. Consultado el 7 de septiembre de 2013.

SILVIA, R. (2013) Talas y repoblaciones de eucaliptos destrozan seis castros inventariados. El País digital, Galicia. Disponible en http://ccaa.elpais.com/ ccaa/2013/01/23/galicia/1358973222 929273.html Consultado 26/12/2013

XUNTA DE GALICIA (1992): Plan Forestal de Galicia. LEY 7/2012, de 28 de junio, de montes de Galicia. Consellería de Agricultura, Ganadería y Montes. Santiago de Compostela. Disponible en: www.xunta.es/dog/Publicados/2012/20120723/ AnuncioC3B0-050712-0001_es.html. Consultado el 8 de agosto de 2013. 